\title{
Molecular Cloning and Characterization of a Wild Eggplant Solanum aculeatissimum NBS-LRR Gene, Involved in Plant Resistance to Meloidogyne incognita
}

\author{
Xiaohui Zhou, Jun Liu, Shengyou Bao, Yan Yang and Yong Zhuang * (1) \\ Jiangsu Key Laboratory for Horticultural Crop Genetic Improvement, Institute of Vegetable Crops, \\ Jiangsu Academy of Agricultural Sciences, Nanjing 210014, China; xhzhou1984@sina.com (X.Z.); \\ kehl_lau@foxmail.com (J.L.); baoshengyou@126.com (S.B.); yzyangyan890618@163.com (Y.Y.) \\ * Correspondence: jaaszy@163.com; Tel.: +86-25-8439-1752
}

Received: 5 January 2018; Accepted: 14 February 2018; Published: 15 February 2018

\begin{abstract}
Root-knot nematodes, Meloidogyne spp., cause considerable damage in eggplant production. Transferring of resistance genes from wild relatives would be valuable for the continued improvement of eggplant. Solanum aculeatissimum, a wild relative of eggplant possessing resistance to Meloidogyne incognita, is potentially useful for genetically enhancing eggplant. In the present study, we have isolated and characterized a nucleotide-binding site leucine-rich repeat (NBS-LRR) resistance gene, designated as SacMi. The full-length cDNA of the SacMi gene was obtained using the technique of rapid-amplification of cDNA ends (RACE). The open reading frame of the SacMi gene was 4014 bp and encoded a protein of 1338 amino acids. Sequence analysis indicated that SacMi belong to the non- Toll/Interleukin-1 receptor (TIR)-NBS-LRR type disease-resistance genes. Interestingly, quantitative RT-PCR showed that SacMi is expressed at low levels in uninfected roots, but was up-regulated by infection with M. incognita. To investigate the role of SacMi in S. aculeatissimum resistance against $M$. incognica, the tobacco rattle virus (TRV)-mediated virus-induced gene silencing (VIGS) system was used. Silencing of SacMi enhanced susceptibility of S. aculeatissimum plants to $M$. incognita, suggesting the possible involvement of $S a c M i$ in resistance against $M$. incognita infection.
\end{abstract}

Keywords: Solanum aculeatissimum; root-knot nematode; resistance; virus-induced gene silencing

\section{Introduction}

Root-knot nematodes (RKNs), Meloidogyne spp., are major parasites of vegetables, causing great economic losses throughout the world, which is especially damaging to solanaceous crops [1,2]. Among Meloidogyne species, Meloidogyne incognita, Meloidogyne arenaria, Meloidogyne javanica, and Meloidogyne hapla are four economically important and destructive species worldwide [1,3]. The parasites infect plant roots and induce the development of 'giant cells'. These alterations greatly affect nutrient partitioning and water uptake in the host plants, resulting in wilted and stunted plants with significantly reduced yield [4-6]. Resistance to root-knot nematode has been identified in several crops or their wild relatives, such as wild tomato, sweet potato and pepper [5-9]. The well-known Mi-1 gene, conferring resistance to the three most economically important root-knot nematode species, $M$. incognita, $M$. arenaria and $M$. javanica, was isolated using a positional mapping approach from a wild relative of cultivated tomato and has been widely used in modern processing tomato cultivars $[5,10,11]$. This single dominant gene shares several structural motifs with other R genes, including nucleotide-binding site (NBS) and leucine-rich repeat (LRR) domains, which are characteristics of a family of plant proteins that are required for resistance against viruses, bacteria, fungi and nematodes $[5,6]$. 
Cultivated eggplant (Solanum melongena) belongs to the Solanaceae family, is an important vegetable crop and is of substantial economic importance in Asia, Africa, and the subtropics [12,13]. However, its production is severely threatened by numerous abiotic or biotic stresses, particularly the root-knot nematodes. According to a conservative estimate, RKNs could cause a 16.67\% yield decline in eggplant production in India, which translates into almost \$23 million annual monetary loss [14]. The broad host range of Meloidogyne spp. makes crop rotation less effective and, due to the adverse effects associated with the use of chemical nematicides, developing plant resistant lines is highly desirable for controlling root-knot nematodes $[15,16]$. Resistance to root-knot nematodes has been identified in some wild relatives of eggplant [17]; however, due to the cross-incompatibility problem between wild Solanum species and S. melongena, research of resistance to RKNs is rather limited.

S. aculeatissimum, a wild relative of cultivated eggplant, is a well-known economically important plant, and is widely cultivated as a medicinal crop, possessing some desirable characteristics, especially the resistance to soil-borne diseases such as verticillium wilt and root-knot nematode [13,18-20]. The successful hybridization between S. aculeatissimum and S. melongena provides the opportunity to utilize resistance genes from S. aculeatissimum [21,22]. In a previous study, we obtained a partial NBS-LRR class resistance gene sequence from transcriptome sequencing of $S$. aculeatissimum, which had a high similarity with Mi-1 gene of tomato [20]. Therefore, in the present study, the full length of this NBS-LRR gene from S. aculeatissimum was cloned by RT-PCR and RACE methods, and its expression pattern against $M$. incognita infection was also analyzed. These findings will be valuable for better understanding and utilizing of resistance genes in S. aculeatissimum.

\section{Results}

\subsection{Isolation and Characterization of SacMi}

A partial cDNA sequence of a NBS-LRR resistance gene was previously obtained from transcriptome sequencing of S. aculeatissimum [20]. To obtain the full-length cDNA sequence, subsequently $5^{\prime}$-RACE and $3^{\prime}$-RACE assays were carried out. The full-length cDNA was obtained and designated as SacMi. The open reading frame (ORF) of SacMi is $4014 \mathrm{bp}$ in length and encodes for a protein with 1338 amino acid residues. The molecular mass of the predicted protein is $153.197 \mathrm{kD}$, and the isoelectric point was calculated to be 4.93. Blastp analysis performed against the PR-proteins in the PRGdb database [23] showed that the SacMi was most similar to the Mi-1.2 and Rpi-blb2 (74.21\% identity at amino acid level).

Specific primers SacMi-F3ORF/SacMi-R6ORF spanning the SacMi ORF were designed to obtain the corresponding DNA sequence. A DNA fragment 4159 bp in length with a start codon ATG and a stop codon TAG was obtained. Comparative analysis of the cDNA and DNA sequence of SacMi transcript region revealed two introns of $88 \mathrm{bp}$ and $57 \mathrm{bp}$ in length, respectively (Figure 1).

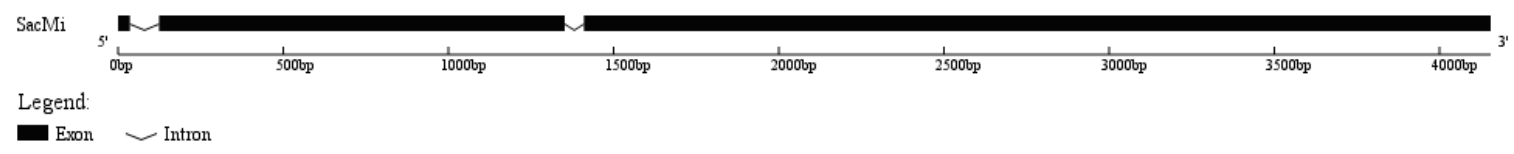

Figure 1. Gene structure of SacMi. Exons are indicated by the black boxes from the predicted translation start site (ATG) and stop codon (TAG) and introns are shown as fold lines.

\subsection{Multiple Sequence Alignment and Phylogenetic Analysis}

Plant NBS-LRR genes can be classified into two types (non-TIR and TIR) based on the presence or absence of a Toll/Interleukin-1 Receptor (TIR) domain at the N-terminus [24]. The NBS domain contains several conserved motifs, including canonical nucleotide-binding kinase 1a or P-loop and Kinase 2 and Kinase 3a, as well as RNBS-A, RNBS-C, GLPL, RNBS-D and MHD. Some are specific to the non-TIR or the TIR-NBS-LRR subfamily, such as RNBS-A-nonTIR and RNBS-D-nonTIR in the nonTIR subclass, and RNBS-A-TIR and RNBS-D-TIR in the TIR subclass [24,25]. Multiple alignments 
of SacMi and other known R genes, including root knot nematode resistance gene Mi-1.2 and CaMi from Solanum lycopersicum and Capsicum annuum, respectively, as well as Solanum lycopersicum Prf, Arabidopsis thaliana RPM1, Solanum bulbocastanum Rpi-blb2, were performed. The presence of conserved NBS domains such as P-loop, Kinase 2, RNBS-A, RNBS-B, GLPL, and the C-terminus LRR domain was revealed in SacMi (Figure 2). Particularly, the presented RNBS-A motifs FDLxKxWVSVSDDF and the amino acid residue Trytophan (W) at the end of Kinase 2 indicated that SacMi belongs to the non-TIR subclass of NBS-LRR resistance genes. Structure analysis of the SacMi protein sequence revealed that the N-terminal region of the predicted protein contained a potential coiled-coil region.

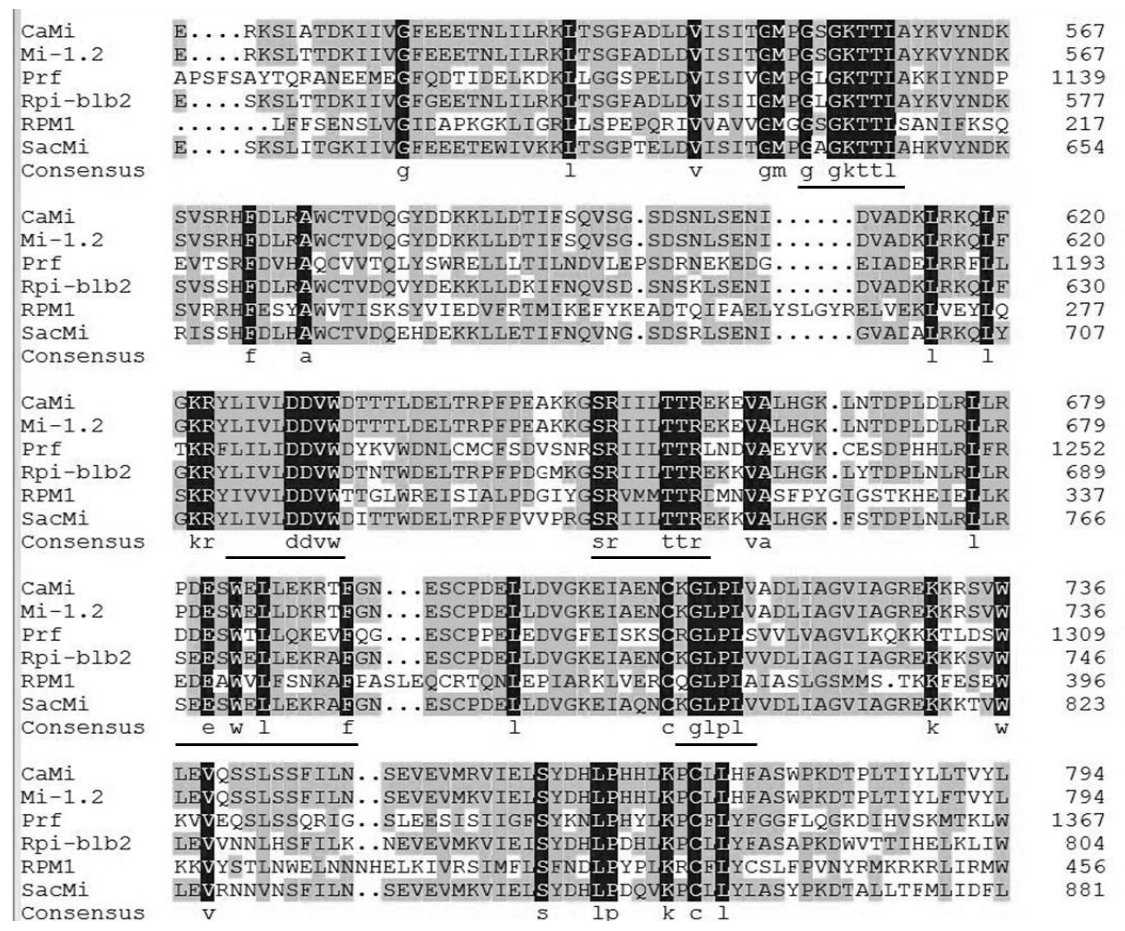

Figure 2. Multiple sequence alignments of the deduced amino acid sequence of SacMi and other R proteins, Mi-1.2 (AAC67238.1), CaMi (ABE68835.1), Prf (AAC49408.1), RPM1 (AGC12590.1), Rpi-blb2 (AAZ95005.1). Nucleotide-binding site (NBS) conserved domains are shaded and indicated by black lines. Black back ground, completely conserved region; Grey back ground, partly conserved region.

To further understand the evolutionary relationships among SacMi and other plant resistance genes, including Solanum lycopersicum Mi-1.2 (AAC67238.1), Capsicum annuum CaMi (ABE68835.1), Solanum lycopersicum Prf (AAC49408.1), Solanum lycopersicum Hero (CAD29729.1), Arabidopsis thaliana RPM1 (AGC12590.1), Solanum bulbocastanum Rpi-blb2 (AAZ95005.1), Solanum tuberosum Gpa2 (AAF04603.1), Gossypium hirsutum GhNTR1 (AIR09519.1), Linum usitatissimum L6 (AAA91022.1), and Linum usitatissimum M (AAB47618.1), a phylogenetic tree was constructed based on the amino acid sequences. As revealed in Figure 3, all resistance genes were clustered into two main groups: the non-TIR-NBS-LRR class and the TIR-NBS-LRR class. In the non-TIR-NBS-LRR group, SacM $i$ was grouped together with Mi-1.2, CaMi, and Rpi-blb2, and shared a high homology with Rpi-blb2. 


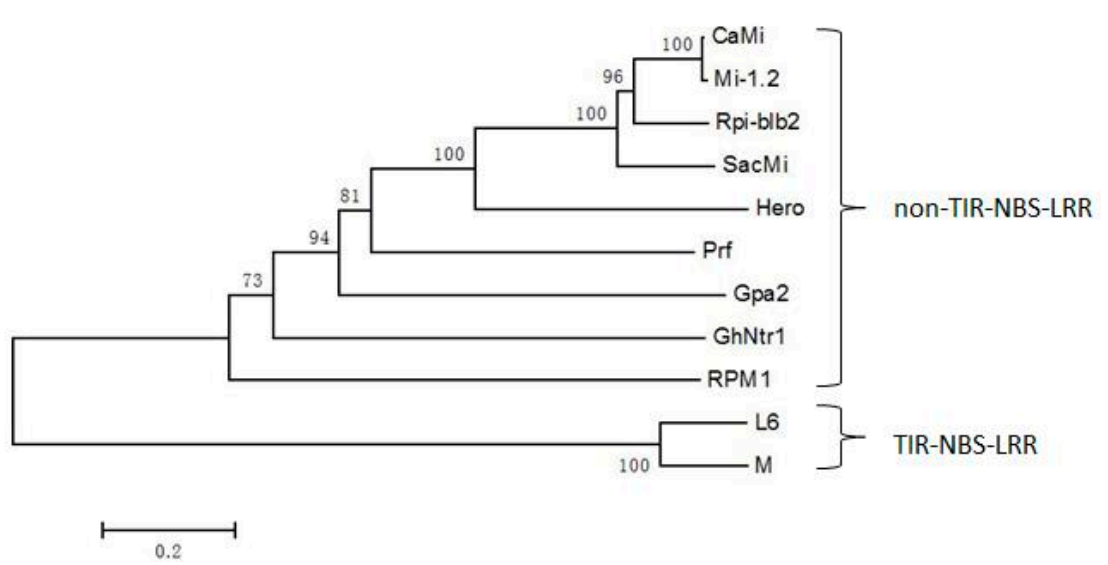

Figure 3. Phylogenetic relationships between SacMi and Mi-1.2 (AAC67238.1), CaMi (ABE68835.1), Prf (AAC49408.1), Hero (CAD29729.1), RPM1 (AGC12590.1), Rpi-blb2 (AAZ95005.1), Gpa2 (AAF04603.1), GhNTR1 (AIR09519.1), L6 (AAA91022.1), M (AAB47618.1) based on amino acid sequences.

\subsection{Expression Analysis of SacMi}

The expression profile of $\mathrm{SacMi}$ in different tissues was analyzed by quantitative real-time PCR (qRT-PCR). The results showed that SacMi expressed in all tissues of leaf, stem and root (Figure 4). The highest expression level of SacMi was detected in leaf tissue, while the expression level of SacMi was relatively low in root tissue.

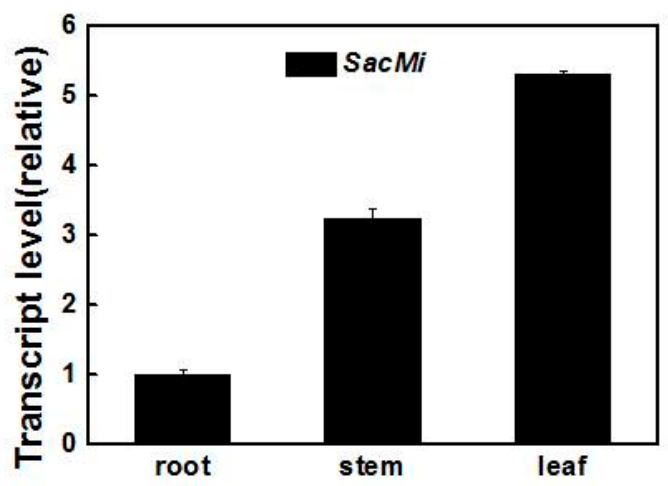

Figure 4. Expression of SacMi gene in different tissues of S. aculeatissimum.

The induction of SacMi expression in response to M. incognita and defense signaling molecules was also analyzed by qRT-PCR. Following infection by M. incognita, the expression of SacMi was induced and peaked at $3 \mathrm{~d}$ after inoculation with 37.86-fold increase. However, the expression level of $\mathrm{SacMi}$ was dropped to 0.38 -fold at $7 \mathrm{~d}$ after inoculation (Figure $5 \mathrm{~A}$ ).

For salicylic acid (SA) treatment, the SacMi expression was increased and reached a peak at $6 \mathrm{~h}$ with a 2.53-fold increase (Figure 5B). For methyl jasmonate (MeJA) treatment, the SacMi expression was gradually induced and reached a maximum at $12 \mathrm{~h}$ with a 3.32-fold increase (Figure 5C). For abscisic acid ABA treatment, the SacMi expression was also induced and peaked at $12 \mathrm{~h}$ with a 2.73 -fold increase (Figure 5D). 

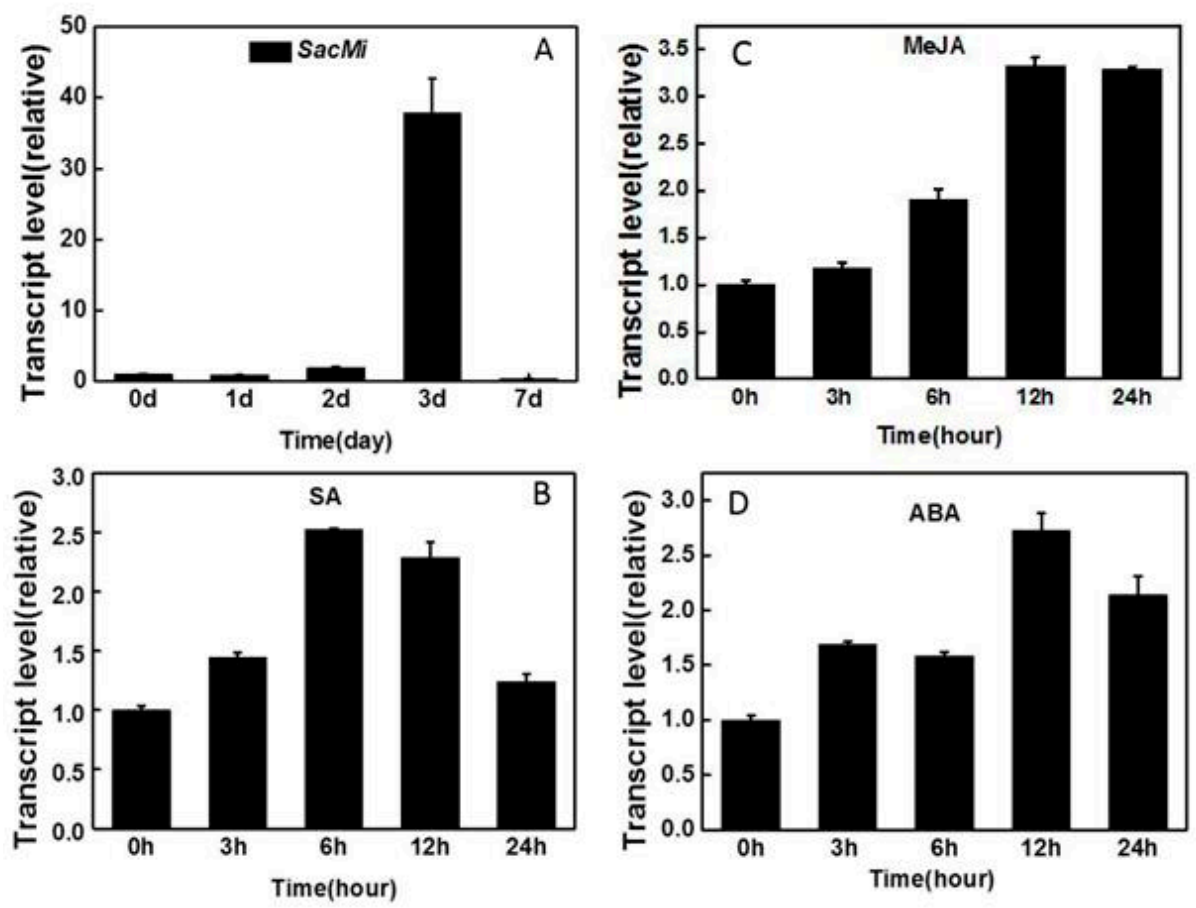

Figure 5. Expression profiles of SacMi gene in response to M. incognita inoculation (A); SA treatment (B);

MeJA treatment (C); and ABA treatment (D).

\subsection{Silencing of SacMi in S. aculeatissmum Using TRV-VIGS}

Virus-induced gene silencing (VIGS) provides an alternative approach for functional analysis of genes. The VIGS system has been established in our lab and is proved to be efficient to induce endogenous gene silencing in S. linnaeanum [26]. Here, we attempted to silence SacMi using tobacco rattle virus (TRV)-mediated gene silencing to determine the role of SacMi. To confirm that the TRV had been inoculated into and had multiplied in the S. aculeatissimum plants, PCR was performed using RNA extracted from newly developed leaves after $20 \mathrm{~d}$ infection with TRV primers (TRV2-F: 5'-TGGGAGATGATACGCTGTT-3', TRV2-R: 5'-CCTAAAACTTCAGACACG-3'). Viral expression was present in the plants inoculated with TRV2 and TRV2-SacMi, and was absent in the plants treated with $\mathrm{H}_{2} \mathrm{O}$ (Figure 6A), which showed that TRV infected the seedlings, transmitted and multiplied from the infiltrating point to other leaves.

qRT-PCR of the transcript levels of SacMi gene in inoculated plants were performed to determine the extent of silencing. RNA extracted from infected leaves after $20 \mathrm{~d}$ infection of S. aculeatissimum agroinfiltrated with empty vector TRV, TRV-SacMi, and $\mathrm{H}_{2} \mathrm{O}$ control were used for qRT-PCR. As shown in Figure 6B, the transcript levels of SacMi mRNA in the plants infiltrated with TRV-SacMi were reduced compared to the control plants (plants infiltrated with empty vector and $\mathrm{H}_{2} \mathrm{O}$ ).

The resistance of TRV-SacMi S. aculeatissimum plants under M. incognita infection was evaluated to determine the possible functional role of SacMi. Six weeks after nematode inoculation, root galls developed on the plants silenced with $\mathrm{SacMi}$, while no root gall was found on the plants agroinfiltrated with an empty TRV vector or $\mathrm{H}_{2} \mathrm{O}$, indicating that silencing of SacMi leads to increased susceptibility to $M$. incognita infection in S. aculeatissimum plants (Figure 6C). 


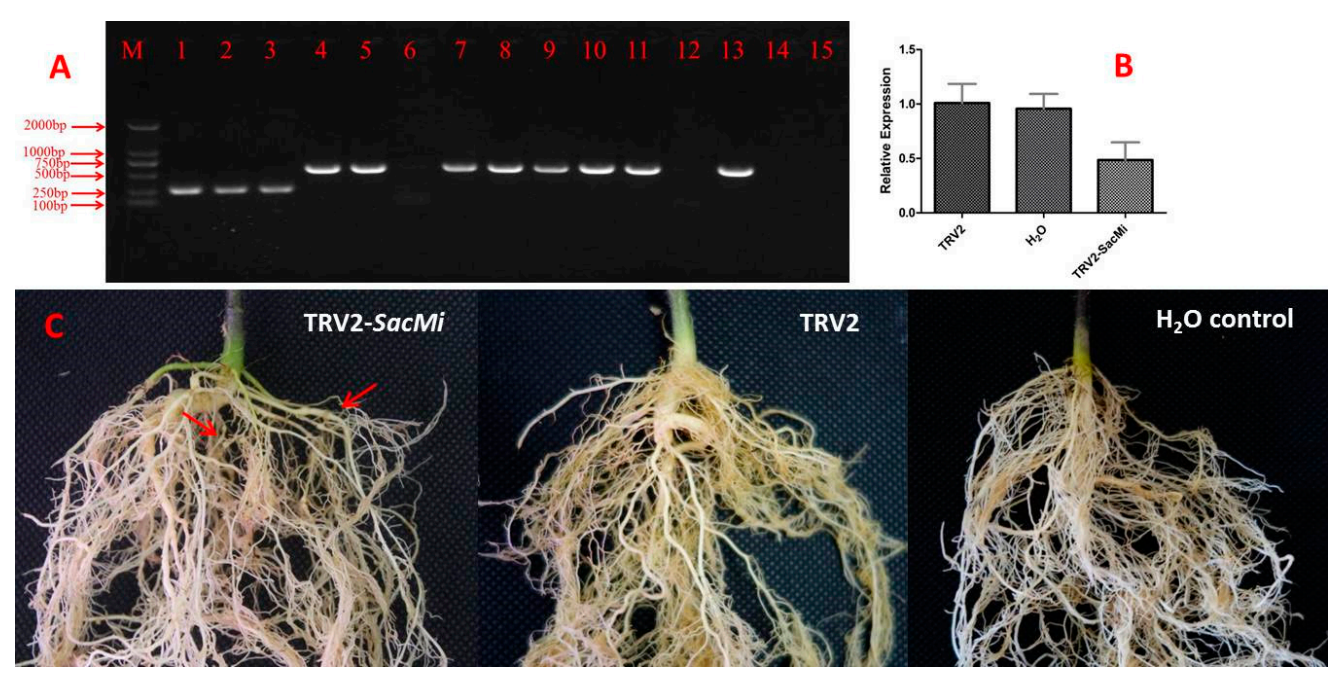

Figure 6. VIGS of SacMi increases the sensitivity to M. incognita in S. aculeatissimum. (A) PCR detection of TRV2-SacMi and TRV transcripts in vivo. M: Marker, 1-3: plants inoculated with TRV2; 4-13: plants inoculated with TRV2-SacMi; 14-15: $\mathrm{H}_{2} \mathrm{O}$ control; (B) qRT-PCR analysis of SacMi mRNA transcript levels in SacMi-silenced plants, empty TRV2 vector control plants and $\mathrm{H}_{2} \mathrm{O}$ control plants; (C) Symptoms of TRV2-SacMi or TRV2 silenced or $\mathrm{H}_{2} \mathrm{O}$ control S. aculeatissimum plalnts infected by M. incognita at six weeks. Red arrows indicate developed root galls.

\section{Discussion}

Wild species are rich sources of genetic diversity for disease resistance in domesticated plants $[27,28]$. The fundamental strategy for controlling RKNs in eggplant is the isolation of resistance genes from their resistant relatives to be used in conventional breeding, genetic engineering and biotechnological approaches. S. aculeatissimum possesses resistance to root-knot nematode, would be a valuable source for eggplant improvement. Based on a partial NBS-LRR gene sequence, which was previously obtained from transcriptome sequencing of S. aculeatissimum, we were able to successfully clone a root-knot nematode resistance gene $\mathrm{SacMi}$, and the structural and phylogenetic analyses of SacMi were presented in this study.

Sequence analysis revealed that SacMi belongs to the NBS-LRR family of plant resistance genes. The deduced protein sequence of SacMi ORF contained typical NBS domains including P-loop, RNBS-A-nonTIR, Kinase-2, RNBS-B, RNBS-C, GLPL, RNBS-D-nonTIR. The conserved NBS region resembles an ATPase domain present in proteins regulating programmed cell death $[29,30]$. The C-terminus LRR domain is considered to be an effector-binding domain, and has been hypothesized to participate in specific recognition of pathogen effector molecules [31]. Evidence is accumulating that NBS-LRR motifs are common in nematode R-genes [2]. Mi-1, Hero, Gpa2, Gro1-4, Cre3 and CaMi have been cloned and all belong to the NBS-LRR gene family [5,6,32-35]. The exception is for $H_{s} 1^{\text {pro-1 }}$, a nematode resistance gene in sugar beet. This much smaller gene encodes a 282-amino acid protein with an N-terminal LRR and a putative membrane-spanning segment [36].

Most plant resistance genes cloned have been reported to be expressed constitutively [36], such as $M i$ [5] and Gpa2 [33]. In this study, the expression patterns of SacMi were investigated to gain insight into its involvement in M. incognita resistance. The SacMi is expressed at low levels in uninfected roots of $S$. aculeatissimum, but infection with $M$. incognita significantly enhanced the expression level of SacMi, indicating that SacMi might be associated with the M. incognita resistance in S. aculeatissimum. Similar expression profiles have been observed for Xa1, a bacterial resistance gene from rice [37], the pib

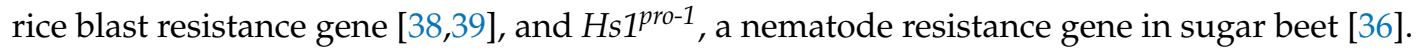


Phytohormones such as salicylic acid (SA), jasmonate (JA), and abscisic acid (ABA) are important regulators in the complex signaling cascades and are involved in the defense responses [40]. SA and JA signaling pathways have been demonstrated to be mutually antagonistic [41], and the ABA has mostly been considered to act as a negative regulator of disease resistance [42]. SA was reported to be an important component of the signaling that leads to $M i-1$-mediated defense response to root-knot nematode in tomato [43], while JA-dependent signaling does not play a role in Mi-1-mediated defense, but an intact JA signaling pathway is required for tomato susceptibility to RKNs [44]. In Arabidopsis, SA treatment increased the expression of SSI4, which encoded a putative protein belonging to the TIR-NBS-LRR class of $\mathrm{R}$ proteins [45]. However, there are also some opposite cases, like Hs $1^{\text {pro-1, }}$, a nematode resistance gene in sugar beet, was not induced by external stimuli including SA, JA, ABA and gibberellic acid (GA). In this study, SacMi was activated not only by SA but also by MeJA and ABA, suggesting SacMi may play a potential role in mediating cross-talk between defense-signaling pathways [36]. The exact role of these hormones and the cross-talk between them during the defense response to RKNs still remains to be discovered.

A number of resistance genes to various plant pathogenic nematodes have been identified in several crops or their wild relatives $[5,6,32-35,46]$. However, the resistance spectrum and genetic properties of these genes are quite different. The previous Mi-1 gene discovered in tomato is temperature sensitive, resistance mediated by the Mi-1 gene is compromised at soil temperatures above $28{ }^{\circ} \mathrm{C}$ [47]. Hare (1956) identified a dominant root knot nematode resistance gene $N$ in C. frutescens, but its ability to confer resistance is rendered ineffective at temperatures over $28^{\circ} \mathrm{C}$ [48]. Temperature sensitivity appears to be a characteristic of several root-knot nematode $\mathrm{R}$ genes in other crop species, including alfalfa [49], sweet patato [50], and cotton [51]. Whether the SacMi gene is also sensitive to high temperature requires further study. In addition, the Mi-1 gene also confers resistance against some isolates of the potato aphid (Macrosiphum euphorbiae) and the sweet potato whitefly (Bemisia tabaci) [11,52]. Although the partial sequence of SacMi gene was obtained from the transcriptome sequencing of S. aculeatissimum in response to Verticillium dahlia, it was not differentially expressed in the Verticillium wilt-treated and control samples. Whether the SacMi gene also provides resistance to other plant pathogens needs further investigation.

This study investigated the existence of root-knot resistance genes in S. aculeatissimum and its possible involvement in M. incognita disease responses. As root-knot nematodes are becoming more and more severe in China because of the increasing use of greenhouses for eggplant production, development of disease-resistant cultivars is an effective and important way of controlling disease. The successful interspecific hybridization between S. aculeatissimum and cultivated eggplant provides the opportunity to transfer useful resistance genes from S. aculeatissimum [22]. The development of specific markers of SacMi for identification of root-knot nematode resistance in interspecific hybrid progeny will facilitate the introgression of resistant genes from S. aculeatissimum to cultivated eggplant.

\section{Materials and Methods}

\subsection{Full-Length cDNA Cloning}

Total RNA was isolated from uninfected roots of S. aculeatissimum seedlings using the RNeasy Plant Mini Kit (Qiagen, Hilden, Germany). A partial cDNA sequence obtained from previous transcriptome sequencing of S. aculeatissimum [20] was used as template. Extension of the $5^{\prime}$ and $3^{\prime}$ RACE were performed with the specific primers (Table 1). $5^{\prime}$ RACE cDNA and $3^{\prime}$ RACE cDNA were synthesized using $5^{\prime} / 3^{\prime}$ RACE kit, 2nd Generation of Roche and $3^{\prime}$ full race core kit of Takara according to the manufacturer's instructions, respectively. Based on the full-length cDNA sequence, the genomic DNA was amplified using specific primers SacMi-F3ORF/SacMi-R6ORF (Table 1). 
Table 1. Primer sequences used in the study to isolate the SacMi gene.

\begin{tabular}{|c|c|c|}
\hline PCR Types & Primers & Primer Sequences $\left(5^{\prime}-3^{\prime}\right)$ \\
\hline $5^{\prime}$ RACE RT & SacMi-R2 & GATTTCTCTTCTAAGTCGCTAA \\
\hline $5^{\prime}$ RACE 1st round RT-PCR & SacMi-R3 & TGTTTCGAGCCCCTGGAGTGCT \\
\hline $5^{\prime}$ RACE 2nd round RT-PCR & SacMi-R4 & TCAGCATGATACTTGGATAGAT \\
\hline $5^{\prime}$ RACE 2nd round RT-PCR & SacMi-R5 & TGACGCAACCATTCACCATCAACCTA \\
\hline $3^{\prime}$ RACE 1st round RT-PCR & SacMi-F2 & TTTCGATCATTGGTATGCCGGGTG \\
\hline DNA sequence amplification & SacMi-F3ORF & ATGGAAAGAGACAAAAGGGAAGC \\
\hline DNA sequence amplification & SacMi-R6ORF & CTAATTAAATAATGGGATATTCATC \\
\hline
\end{tabular}

\subsection{Bioinformatics Analysis}

Homology searches were performed using BLASTX from NCBI [53]. The conserved domain was predicted by the Conserved Domain Database (CDD) [54] from NCBI. The molecular mass and theoretical isoelectric point $(\mathrm{pI})$ were predicted on the ExPASy website [55]. Potential coiled-coil structures were predicted by the COILS program [56,57]. Multiple sequence alignment and phylogenetic tree were carried out by DNAMAN software (version 6.0, Lynnon Biosoft, CA, USA) and MEGA version 6.0 [58,59]. The aligned full-length sequence data were used for the phylogenetic tree using the neighbor-joining method with 1000 bootstraps. Structure of SacMi gene was generated using GSDS 2.0 (Center for Bioinformatics (CBI), Peking University, Beijing, China) [60].

\subsection{Plant Material, Pathogen Inoculation, and Hormone Treatments}

S. aculeatissimum seeds were sown in sterilized soil and cultured at $25{ }^{\circ} \mathrm{C} / 15{ }^{\circ} \mathrm{C}$, with a photoperiod of $16 \mathrm{~h}$ light and $8 \mathrm{~h}$ dark in the greenhouse of Jiangsu Academy of Agricultural Sciences, Nanjing, China. The samples of roots, stems and leaves of S. aculeatissimum were harvested at the fourth true-leaf stage, prior to exposure to treatments.

For M. incognita inoculation, the original culture of M. incognita was kindly provided by Professor Chen Jinfeng in the Department of Horticulture at Nanjing Agricultural University. Egg inocula were extracted from infected roots of susceptible tomato cultivar Moneymaker using $0.5 \%$ sodium hypochlorite $(\mathrm{NaClO})$ [61]. Seedlings at the fourth true-leaf stage were inoculated with 3000 eggs of M. incognita in $3 \mathrm{~mL}$ tap water [62]. Control plants were not inoculated but were treated and sampled with distilled water in the same way. The root samples were harvested at $0,1,2,3 \mathrm{~d}$ and $7 \mathrm{~d}$ post-inoculation.

For hormone treatments, seedlings at the fourth true-leaf stage were sprayed with $2 \mathrm{mM}$ salicylic acid (SA), $100 \mu \mathrm{M}$ methyl jasmonate (MeJA) and $100 \mu \mathrm{M}$ abscisic acid (ABA), respectively. Control plants were treated with distilled water in the same way. The leaf samples were collected at the following points: $0,3,6,12$ and $24 \mathrm{~h}$.

Three independent biological replications were performed for each treatment mentioned above, and twenty plants were used in each of the replicates. All the freshly collected samples mentioned above were immediately frozen in liquid nitrogen and stored at $-80^{\circ} \mathrm{C}$ until use. Three independent biological replications were performed for each experiment.

\subsection{Quantitative Real-Time PCR Analysis}

The expression patterns in different tissues (root, stem and leaf) and under M. incognita infection, as well as phytohormone treatments, were determined using qRT-PCR. Primers (forward: 5'-CACCCGTGCTTTCCTATTCG- ${ }^{\prime}$ and reverse: $5^{\prime}$-GGGCAGTCTCGCTATTGTTG- $3^{\prime}$ ) were designed using Primer 3 software (version 4.0) [63,64]. The glyceraldehyde-3-phosphate dehydrogenase $(\mathrm{GAPDH})$ gene of eggplant was used as internal control using the following primers, forward: 5'-CCGCTCCTAGCAAAGATGCC-3' and reverse: 5'-ACCCTCCACAATGCCAAACC-3'. qRT-PCR was performed on the Roche lightcycle 480 system II using a SYBR Green-based PCR assay. Three independent biological replicates of each sample and three technical replicates of each biological 
replicate were used for qRT-PCR analysis. The reaction containing $10 \mu \mathrm{L}$ of diluted cDNAs, and $0.4 \mu \mathrm{L}$ of each primer to a final volume of $20 \mu \mathrm{L}$ was performed. The PCR conditions were $95{ }^{\circ} \mathrm{C}$ for $30 \mathrm{~s}$, followed by 40 cycles of $95^{\circ} \mathrm{C}$ for $5 \mathrm{~s}, 60^{\circ} \mathrm{C}$ for $30 \mathrm{~s}$. Relative gene expression levels were calculated using the $2^{-\Delta \Delta \mathrm{Ct}}[65]$.

\subsection{VIGS of SacMi in S. aculeatissimum}

The tobacco rattle virus (TRV)-based VIGS system was employed for SacMi silencing. The TRV vectors used in this study were described previously [26]. A 330-bp cDNA fragment, spanning the carboxy terminal end of the SacMi gene, was cloned into pTRV2 using gene specific primers (forword primer: 5'-CAGGATCCGGCGGATAAGTTCAAGTGC-3' , reverse primer: 5'-GACGGTACCGAGAAAGAAGCAGGCAGAG-3'). The TRV1, empty TRV2, and TRV2-SacMi plasmid were then transformed into Agrobacterium tumefaciens strain GV3101, respectively. An equal volume of TRV1 Agrobacterium culture was mixed with empty TRV2 or TRV2-SacMi cultures before infiltration. The mixture was infiltrated into cotyledons of $15 \mathrm{~d}$ S. aculeatissimum plants using $1 \mathrm{~mL}$ needleless syringe. Seedlings were maintained for 3 weeks in a growth chamber at $22{ }^{\circ} \mathrm{C}$. At $20 \mathrm{~d}$ post-virus inoculation, the plants were infected by $M$. incognita, and then transferred into growth room with a relative humidity of $70 \%$, under a $16 / 8 \mathrm{~h}$ photoperiod.

Acknowledgments: This work was supported by the National Key Research and Development Program of China (2017YFD0101900), National Natural Science Foundation of China (31672145, 31701932), Key Research Program of Jiangsu Province (BE2016329).

Author Contributions: Yong Zhuang, Xiaohui Zhou, Jun Liu conceived and designed the experiments; Xiaohui Zhou, Jun Liu, Shengyou Bao and Yan Yang performed the experiments; Xiaohui Zhou and Jun Liu analyzed the data; Xiaohui Zhou wrote the paper.

Conflicts of Interest: The authors declare no conflict of interest.

\section{Abbreviations}

$\begin{array}{ll}\text { NBS } & \text { Nucleotide binding site } \\ \text { LRR } & \text { Leucine-rich repeat } \\ \text { TIR } & \text { Toll/Interleukin-1 receptor } \\ \text { TRV } & \text { Tobacco rattle virus } \\ \text { VIGS } & \text { Virus-induced gene silencing } \\ \text { ORF } & \text { Open reading frame } \\ \text { qRT-PCR } & \text { Quantitative real-time PCR } \\ \text { SA } & \text { Salicylic acid } \\ \text { MeJA } & \text { Methyl jasmonate } \\ \text { ABA } & \text { Abscisic acid } \\ \text { GA } & \text { Gibberellic acid } \\ \text { RACE } & \text { Rapid-amplification of cDNA ends }\end{array}$

\section{References}

1. Castagnone-Sereno, P. Genetic variability and adaptive evolution in parthenogenetic root-knot nematodes. Heredity 2006, 96, 282-289. [CrossRef] [PubMed]

2. Djian-Caporalino, C.; Fazari, A.; Arguel, M.J.; Vernie, T.; VandeCasteele, C.; Faure, I.; Brunoud, G.; Pijarowski, L.; Palloix, A.; Lefebvre, V.; et al. Root-knot nematode (Meloidogyne spp.) Me resistance genes in pepper (Capsicum annuum L.) are clustered on the P9 chromosome. Theor. Appl. Genet. 2007, 114, 473-486. [CrossRef] [PubMed]

3. Walters, S.A.; Barker, K.R. Current distribution of five major Meloidogyne species in the United States. Plant Dis. 1994, 78, 772-774. [CrossRef]

4. Trudgill, D.L. Parthenogenetic root-knot nematodes (Meloidogyne spp.); how can these biotrophic endoparasites have such an enormous host range? Plant Pathol. 1997, 46, 26-32. [CrossRef] 
5. Milligan, S.B.; Bodeau, J.; Yaghoobi, J.; Kaloshian, I.; Zabel, P.; Williamson, V.M. The root knot nematode resistance gene $\mathrm{Mi}$ from tomato is a member of the leucine zipper, nucleotide binding, leucine-rich repeat family of plant genes. Plant Cell 1998, 10, 1307-1319. [CrossRef] [PubMed]

6. Chen, R.G.; Li, H.X.; Zhang, L.Y.; Zhang, J.H.; Xiao, J.H.; Ye, Z.B. CaMi, a root-knot nematode resistance gene from hot pepper (Capsium annum L.) confers nematode resistance in tomato. Plant Cell Rep. 2007, 26, 895-905. [CrossRef] [PubMed]

7. Williamson, V.M.; Hussey, R.S. Nematode pathogenesis and resistance in plants. Plant Cell 1996, 8, 1735-1745. [CrossRef] [PubMed]

8. Williamson, V.M.; Kumar, A. Nematode resistance in plants: The battle underground. Trends Genet. 2006, 22, 396-403. [CrossRef] [PubMed]

9. Niu, C.; Hinchliffe, D.; Cantrell, R.; Wang, C.Y.; Roberts, P.; Zhang, J. Identification of molecular markers associated with root-knot nematode resistance in upland cotton. Crop Sci. 2007, 47, 951-960. [CrossRef]

10. Williamson, V.M. Root-knot nematode resistance genes in tomato and their potential for future use. Annu. Rev. Phytopathol. 1998, 36, 277-293. [CrossRef] [PubMed]

11. Nombela, G.; Williamson, V.M.; Muniz, M. The root-knot nematode resistance gene Mi-1.2 of tomato is responsible for resistance against the whitefly Bemisia tabaci. Mol. Plant Microbe Interact. 2003, 16, 645-649. [CrossRef] [PubMed]

12. Collonnier, C.; Fock, I.; Kashyap, V.; Rotino, G.L.; Daunay, M.C.; Lian, Y.; Mariska, I.K.; Rajam, M.V.; Servaes, A.; Ducreux, G.; et al. Applications of biotechnology in eggplant. Plant Cell Tissue Organ Cult. 2001, 65, 91-107. [CrossRef]

13. Zhuang, Y.; Zhou, X.H.; Wang, S.B. Genetic diversity of NBS-LRR class disease-resistance gene analogs in cultivated and wild eggplants. Plant Syst. Evol. 2012, 298, 1399-1406. [CrossRef]

14. Jain, R.K.; Mathur, K.N.; Singh, R.V. Estimation of losses due to plant parasitic nematodes on different crops in India. Indian J. Nematol. 2007, 37, 219-221.

15. Kinloch, R.A.; Hiebsch, C.K.; Peacock, A.A. Comparative root-knot galling and yield responses of soybean cultivars to Meloidogyne incognita. Plant Dis. 1985, 69, 334-336.

16. Jacquet, M.; Bongiovanni, M.; Martinez, M.; Verschave, P.; Wajnberg, E.; Castagnone-Sereno, P. Variation in resistance to the root-knot nematode Meloidogyne incognita in tomato genotypes bearing the Mi gene. Plant Pathol. 2005, 54, 93-99. [CrossRef]

17. Bagnaresi, P.; Sala, T.; Irdani, T.; Scotto, C.; Lamontanara, A.; Beretta, M.; Rotino, G.L.; Sestili, S.; Cattivelli, L.; Sabatini, E. Solanum torvum responses to the root-knot nematode Meloidogyne incognita. BMC Genom. 2013, 14, 540. [CrossRef] [PubMed]

18. Handique, A.K. Breeding behavior of Solanum khasianum Clarke. Euphytica 1986, 35, 631-632. [CrossRef]

19. Borua, P.K. Failure in an interspecific cross between Solanum khasianum Clarke and Solanum mammosum L. Euphytica 1990, 46, 1-6. [CrossRef]

20. Zhou, X.H.; Bao, S.Y.; Liu, J.; Zhuang, Y. De novo sequencing and analysis of the transcriptome of the wild eggplant species Solanum aculeatissimum in response to Verticillium dahliae. Plant Mol. Biol. Rep. 2016, 34, 1193-1203. [CrossRef]

21. Rattan, P.; Kumar, S.; Salgotra, R.K.; Samnotra, R.K.; Sharma, F. Development of interspecific $F_{1}$ hybrids (Solanum melongena $\times$ Solanum Khasianum) in eggplant through embryo rescue technique. Plant Cell Tissue Organ Cult. 2015, 120, 379-386. [CrossRef]

22. Zhou, X.H.; Bao, S.Y.; Liu, J.; Zhuang, Y. Production and characterization of an amphidiploid derived from interspecific hybridization between Solanum melongena L. and Solanum aculeatissimum Jacq. Sci. Hortic. 2018, 230, 102-106. [CrossRef]

23. Pathogen Receptor Genes Database. Available online: http://www.prgdb.org (accessed on 8 April 2017).

24. Meyers, B.C.; Kozik, A.; Griego, A.; Kuang, H.; Michelmore, R.W. Genome-wide analysis of NBS-LRR-Encoding genes in Arabidopsis. Plant Cell 2003, 15, 809-834. [CrossRef] [PubMed]

25. Wan, H.J.; Zhao, Z.G.; Malik, A.A.; Qian, C.T.; Chen, J.F. Identification and characterization of potential NBS-encoding resistance genes and induction kinetics of a putative candidate gene associated with downy mildew resistance in Cucumis. BMC Plant Biol. 2010, 10, 186. [CrossRef] [PubMed]

26. Liu, J.; Zhou, X.H.; Feng, C.; Wu, W.; Zhuang, Y. The function confirmation of Ve gene homolog in S. linnaeanum related to Verticillium wilt resistance by VIGS. Acta Agric. Boreali-Sin. 2014, 29, $217-221$. 
27. Tanksley, S.D.; McCouch, S. Seed banks and molecular maps: Unlocking the genetic potential from the wild. Science 1997, 277, 1063-1066. [CrossRef] [PubMed]

28. Michelmore, R.W. The impact zone: Genomics and breeding for durable disease resistance. Curr. Opin. Plant Biol. 2003, 6, 397-404. [CrossRef]

29. Van der Biezen, E.; Jones, J. The NB-ARC domain: A novel signaling motif shared by plant resistance gene products and regulators of cell death in animals. Curr. Biol. 1998, 8, 226-227. [CrossRef]

30. Aravind, L.; Dixit, V.; Koonin, E. The domains of death: Evolution of the apoptosis machinery. Trends Biol. Sci. 1999, 24, 47-53. [CrossRef]

31. De Young, B.J.; Inners, R.W. Plant NBS-LRR proteins in pathogen sensing and host defense. Nat. Immunol. 2006, 7, 1243-1249. [CrossRef] [PubMed]

32. Ernst, K.; Amar, K.; Doris, K. The broad-spectrum potato cyst nematode resistance gene (Hero) from tomato is the only member of a large gene family of NBS-LRR genes with an unusual amino acid repeat in the LRR region. Plant J. 2002, 31, 127-136. [CrossRef] [PubMed]

33. Van der Vossen, E.A.G.; van der Voort, J.; Kanyuka, K.; Bendahmane, A.; Sandbrink, H.; Baulcombe, D.C.; Bakker, J.; Stiekema, J.; Klein-Lankhorst, R.M. Homologues of a single resistance-gene cluster in potato confer resistance to distinct pathogens: A virus and a nematode. Plant J. 2000, 23, 567-576. [CrossRef] [PubMed]

34. Paal, J.; Henselewski, H.; Muth, J.; Meksem, K.; Menendez, C.M.; Salamini, F.; Ballvora, A.; Gebhardt, C. Molecular cloning of the potato Gro1-4 gene conferring resistance to pathotype Ro1 of the root cyst nematode Globodera rostochiensis, based on a candidate gene approach. Plant J. 2004, 38, 285-297. [CrossRef] [PubMed]

35. Lagudah, E.S.; Moullet, O.; Appels, R. Map based cloning of a gene sequence encoding a nucleotide binding domain and leucine rich region at the Cre3 nematode resistance locus of wheat. Genome 1997, 40, 659-665. [CrossRef] [PubMed]

36. Thurau, T.; Sirak, K.; Jung, C.; Cai, D. The promoter of the nematode resistance gene Hs $1^{\text {pro-1 }}$ activates a nematode-responsive and feeding site-specific gene expression in sugar beet (Beta vulgaris L.) and Arabidopsis thaliana. Plant Mol. Biol. 2003, 52, 643-660. [CrossRef] [PubMed]

37. Yoshimura, S.; Yamanouchi, U.; Katayose, Y.; Toki, S.; Wang, Z.X.; Kono, I.; Kurata, N.; Yano, M.; Iwata, N.; Sasaki, T. Expression of Xa1, a bacterial blight-resistance gene in rice, is induced by bacterial inoculation. Proc. Natl. Acad. Sci. USA 1998, 95, 1663-1669. [CrossRef] [PubMed]

38. Wang, Z.X.; Yano, M.; Yamanouchi, U.; Iwamoto, M.; Monna, L.; Hayasaka, H.; Katayose, Y.; Sasaki, T. The $P i b$ gene for rice blast resistance belongs to the nucleotide binding and leucine-rich repeat class of plant disease resistance genes. Plant J. 1999, 19, 55-64. [CrossRef] [PubMed]

39. Wang, Z.X.; Yano, M.; Yamanouchi, U.; Katayose, Y.; Iwamoto, M.; Sasaki, T.; Yano, M. Expression of the $P i b$ rice-blast-resistance gene family is up-regulated by environmental conditions favoring infection and by chemical signals that trigger secondary plant defences. Plant Mol. Biol. 2001, 47, 653-661. [CrossRef] [PubMed]

40. Bari, R.; Jones, J.D. Role of plant hormones in plant defense responses. Plant Mol. Biol. 2009, 69, 473-488. [CrossRef] [PubMed]

41. Kunkel, B.N.; Brooks, D.M. Cross talk between signaling pathways in pathogen defense. Curr. Opin. Plant Biol. 2002, 5, 325-331. [CrossRef]

42. Flors, V.; Ton, J.; van Doorn, R.; Jakab, G.; Garcia-Agustin, P.; Mauch-Mani, B. Interplay between JA, SA and ABA signaling during basal and induced resistance against Pseudomonas syringae and Alternaria brassicicola. Plant J. 2007, 1, 81-92. [CrossRef] [PubMed]

43. Branch, C.; Hwang, C.F.; Navarre, D.A.; Williamson, V.M. Salicylic acid is part of the Mi-1-mediated defense response to root-knot nematode in tomato. Mol. Plant-Microbe Interact. 2004, 17, 351-356. [CrossRef] [PubMed]

44. Bhattarai, K.K.; Xie, Q.G.; Mantelin, S.; Bishnoi, U.; Girke, T.; Navarre, D.A.; Kaloshian, I. Tomato susceptibility to root-knot nematodes requires an intact jasmonic acid signaling pathway. Mol. Plant-Microbe Interact. 2008, 21, 1205-1214. [CrossRef] [PubMed]

45. Shirano, Y.; Kachroo, P.; Shah, J.; Klessig, D.F. A Gain-of-Function mutation in an Arabidopsis Toll Interleukin 1 receptor-nucleotide binding site-leucine-rich repeat type $\mathrm{R}$ gene triggers defense responses and results in enhanced disease resistance. Plant Cell 2002, 14, 3149-3162. [CrossRef] [PubMed]

46. Cai, D.G.; Kleine, M.; Kifle, S. Positional cloning of a gene for nematode resistance in sugar beet. Science 1997, 275, 832-834. [CrossRef] [PubMed] 
47. Ammati, M.; Thomason, I.; McKinney, H. Retention of resistance to Meloidogyne incognita in Lycopersicon genotypes at high soil temperature. J. Nematol. 1986, 18, 491-495. [PubMed]

48. Hare, W.W. Resistance in pepper to Meoidogyne inncognita. Phytopathology 1956, 46, 98-104.

49. Griffin, G.D. Effects of temperature on Meloidogyne hapla in alfalfa. Phytopathology 1969, 59, 599-602.

50. Jatala, P.; Russell, C.C. Nature of sweet potato resistance to Meloidogyne incognita and the effects of temperature on parasitism. J. Nematol. 1972, 4, 1-7. [PubMed]

51. Carter, W.W. Influence of soil temperature on Meloidogyne incognita resistant and susceptible cotton, Gossypium hirsutum. J. Nematol. 1982, 14, 343-346. [PubMed]

52. Rossi, M.; Goggin, F.L.; Milligan, S.B.; Kaloshian, I.; Ullman, D.E.; Williamson, V.W. The nematode resistance gene Mi of tomato confers resistance against the potato aphid. Proc. Natl. Acad. Sci. USA 1998, 95, 9750-9754. [CrossRef] [PubMed]

53. National Center for Biotechnology Information. Available online: http://www.ncbi.nlm.nih.gov/ (accessed on 7 April 2017).

54. Conserved Domain Database. Available online: https://www.ncbi.nlm.nih.gov/structure/cdd/wrpsb.cgi (accessed on 7 April 2017).

55. ExPASy. Available online: http://www.expasy.org/tools (accessed on 18 April 2017).

56. Lupas, A. Prediction and analysis of coiled-coil structures. Methods Enzymol. 1996, 266, 513-525. [PubMed]

57. EMBnet Node Switzerland. Available online: http:/ / www.ch.embnet.org (accessed on 14 August 2017).

58. Tamura, K.; Stecher, G.; Peterson, D.; Filipski, A.; Kumar, S. MEGA 6: Molecular Evolutionary Genetics Analysis version 6.0. Mol. Biol. Evol. 2013, 30, 2725-2729. [CrossRef] [PubMed]

59. Molecular Evolutionary Genetics Analysis. Available online: http:/ / www.megasoftware.net (accessed on 18 April 2017).

60. Hu, B.; Jin, J.P.; Guo, A.Y.; Zhang, H.; Luo, J.C.; Gao, G. GSDS 2.0: An upgraded gene feature visualization server. Bioinformatics 2015, 31, 1296-1297. [CrossRef] [PubMed]

61. Hussey, R.S.; Barker, K.R. A comparison of methods of collecting inocula of Meloidogyne spp. including a new technique. Plant Dis. Rep. 1973, 57, 1025-1028.

62. Thies, J.A.; Ariss, J.J. Comparison between the $N$ and $M e 3$ genes conferring resistance to the root-knot nematode (Meloidogyne incognita) in genetically different pepper lines (Capsicum annuum). Eur. J. Plant Pathol. 2009, 125, 545-550. [CrossRef]

63. Rozen, S.; Skaletsky, H. Primer 3 on the WWW for general users and for biologist programmers. Methods Mol. Biol. 2000, 132, 365-386. [PubMed]

64. Primer3web. Available online: http:/ / primer3.ut.ee (accessed on 18 April 2017).

65. Livak, K.J.; Schmittgen, T.D. Analysis of relative gene expression data using real-time quantitative PCR and the $2^{-\Delta \Delta C}$ T Method. Methods 2001, 25, 402-408. [CrossRef] [PubMed]

(C) 2018 by the authors. Licensee MDPI, Basel, Switzerland. This article is an open access article distributed under the terms and conditions of the Creative Commons Attribution (CC BY) license (http://creativecommons.org/licenses/by/4.0/). 